\title{
Impact of Precipitation Rate Assimilation over India and Surrounding Regions
}

\author{
Surya K. Dutta ${ }^{1} \&$ V. S. Prasad ${ }^{1}$ \\ ${ }^{1}$ National Centre for Medium Range Weather Forecasting, Noida, India \\ Correspondence: Surya K. Dutta, Project Scientist-C, National Centre for Medium Range Weather Forecasting, \\ A-50, Institutional Area, Sector-62, Phase-II, Noida 201307, U.P., India. E-mail: dutta_surya@yahoo.co.in \& \\ surya@ncmrwf.gov.in
}

Received: June 4, 2012 Accepted: July 9, 2012 Online Published: September 20, 2012

doi:10.5539/esr.v2n1p74 URL: http://dx.doi.org/10.5539/esr.v2n1p74

\begin{abstract}
An Observation System Experiment has been described that examines the impact of precipitation rate, obtained from SSM/I onboard the DMSP satellites and those from the TRMM. Analysis scheme used is Gridpoint Statistical Interpolation (GSI) with the forecast model T254L64. Analyses are carried out globally for four times daily at six hourly intervals from $00 \mathrm{z}$ to $18 \mathrm{z}$. Two sets of simulations were performed. Precipitation rate measured by SSM/I and TRMM are assimilated and subsequently forecasts for 168 hour are made through the NCMRWF's GFS for the entire month of June-2009. The analyses and forecasts are also repeated for the entire period without assimilating the precipitation rate data. The results are analyzed globally giving special emphasis over India and surrounding regions. When compared with the observations, improvement of analyses and forecasts from experimental simulations were noticed. Analyses versus observation study showed improvement in terms of lower RMSE over both Tropics and Indian region. Positive impact on temperature analysis is seen over all the three levels of 850,500 and $250 \mathrm{hPa}$. For vector wind and geo-potential height analysis positive impact of assimilation is seen over 500 and $250 \mathrm{hPa}$ pressure levels. In forecast versus analysis comparison, the differences in the values from the two simulations are mostly insignificant. For a few cases, the experimental simulations shows significant improvement over the control runs. When compared with the observations, consistent improvement in the experimental forecast in terms of lower RMSE is found over both Tropics and Indian region. Improvement in all the three parameters (temperature, horizontal wind and geo-potential height) is observed.
\end{abstract}

Keywords: precipitation rate, SSMI, TRMM, OSE, GSI, assimilation

\section{Introduction}

The understanding of the variability of the atmospheric moisture content, latent heat, clouds and the large scale atmospheric circulation with the variation in the change in atmospheric conditions is primarily required for understanding the response of earth's weather and climate to atmospheric perturbations. The analysis of the conventional and the non-conventional data collected from various sources helps in the understanding of the atmospheric processes directly and indirectly, i.e. through the use in numerical weather prediction. Satellite data serves as an important source of information, especially over the oceanic regions where the other modes of observations are very scarce. Observations from conventional sources have a low spatial density, randomly distributed over the land surface. Satellites on the other hand scan wide areas along their orbital track providing voluminous data which is widely used in improving the analysis for the numerical weather prediction models. Satellites serve as the source of measurements of atmospheric variables with high spatial and temporal resolution. Satellites however mostly measure the parameters indirectly. Various meteorological variables are retrieved from their measured Brightness Temperatures. Observations from satellite microwave soundings have proved to be the most vital information source in providing quantitative measurements of various atmospheric quantities (Stanley \& Thomas, 1995; Gelaro et al., 2010). There have been limitations in the present day systems, restricting the assimilation of satellite data to clear-sky regions for infrared radiances and to non-precipitating areas for microwave radiances. In the recent years, varied studies have been made towards evaluating the potential of assimilation of satellite data over cloudy and rainy regions using 3D/4D-Var systems (Chevallier et al., 2002; Janisková et al., 2002; Moreau et al., 2004). 
Accurate precipitation forecast is one of the most crucial and difficult part of numerical weather prediction. The rainfall patterns and distribution is different over different regions of the earth. In the past the lacuna in the volume of rainfall observations in the tropics was the primary difficulty in quantifying errors in precipitation forecast and their impact on the model analyses. The quality and the quantity of the physically retrieved rainfall estimates has enhanced and improved with the use of satellite-borne microwave instruments. Deficiencies in the NWP models towards rainfall forecast can be adjusted to certain extent by assimilating the satellite derived rainfall estimates. Use of satellite-derived precipitation rate (PR) in diabatic or physical initialization not only reduces the model spin-up, but also improves the short-range forecast. This in turn improves the first guess used for the subsequent analysis cycle (Krishnamurti et al., 1984; 1991; 1993; Donner, 1988; Turpeinen et al., 1990; Puri \& Miller, 1990; Heckley et al., 1990; Mathur et al., 1992; Kasahara et al., 1994; Manobianco et al., 1994; Van Tuyl, 1996; Peng \& Chang, 1996; Treadon, 1996; 1997). Despite the proven positive impact of precipitation rate assimilation on forecast, the methodology has certain drawbacks. Precipitation estimates of short range forecasts have spin-up effects, and the model is able to hold very little of the improvement beyond $24 \mathrm{~h}$. Moreover, the rainfall retrieval algorithms can have influence on the extent of the impact of physical initialization over forecasts (Krishnamurti et al., 1994).

Being an indirect model variable in two dimensional space, precipitation rate (PR) cannot be assimilated in a straightforward manner similar to the conventional parameters of wind, temperature and specific humidity. Through special retrieval algorithm, the vertical profile of humidity can be constructed using PR observations. Earlier, there were two distinct methodologies for PR assimilation. Either the convective heating terms of the NWP model equations were modified according to the observed precipitation rate (Fiorino \& Warner, 1981; Donner, 1988) or the vertical profile of moisture and temperature field were adjusted for the convective parameterization schemes to produce an initially specified heating rate (Krishnamurti et al., 1984; Krishnamurti \& Bedi, 1988). In another scheme of precipitation rate assimilation called 'latent heat nudging' developed by Jones et al. (1997), the latent heat profiles from the NWP models are scaled by the ratio of observed to model precipitation rates. This results in the adjustment of the diagnosed precipitation rate more closely towards observations. In all the above schemes it was found that incorporation of the observed precipitation rate leads to an improvement in the model forecasts. Variational data assimilation of precipitation rate was also explored by several authors. To mention, the assimilation work of surface rainfall observations by Zupanski and Mesinger (1995) and Zou and Kuo (1996) are of noted significance. They all received positive impact on quantitative precipitation forecast. The variational approach of assimilation has certain advantage over other schemes. It does not require various pre-processing or retrieval operations. It accepts the observed precipitation rate in both convective and non-convective form and produces a more dynamically consistent initial condition (IC).

In the following part section 2 provides a brief description of the PR observations used in the study. Section 3 describes the experimental setup. Results and discussions are in section 4, followed by conclusion in section 5 .

\section{Precipitation Rate Data}

For the present observation system experiment, precipitation rate from SSM/I onboard DMSP satellites and that measured by TRMM have been used. The precipitation rate data used are the derived products packed in WMO (World Meteorological Organization) BUFR (Binary Universal Format).

\subsection{SSM/I Precipitation Rate}

SSM/I (Special Sensor Microwave/Imager) is a passive microwave radiometer onboard the DMSP (Defense Meteorological Satellite Program) satellites. These satellites flow in sun-synchronous orbits having an inclination of $98.8^{0}$ and cross the equator at 1704 LST. Six series of DMSP satellites viz. F-8, F-10, F-11, F-13, F14 and F15 have been launched since 1987. Presently, on the DMSP's F-16, F-17 and F-18 satellites, the SSM/I are replaced by the SSM/IS (Special Sensor Microwave Imager Sounder). SSM/I have seven channels operating at frequencies of 19.35, 22.235, 37.0 and $85.5 \mathrm{GHz}$. Except for the $22.235 \mathrm{GHz}$ channel which has only vertical polarization; all the other channels have both vertical and horizontal polarizations. The SSM/I measures upwelling microwave radiation at spatial intervals ranging from $12.5 \mathrm{~km}$ at $85.5 \mathrm{GHz}$ to $25 \mathrm{~km}$ at $19.35,22.235$ and $37.0 \mathrm{GHz}$. The sensor footprints range in diameter from $55 \mathrm{~km}$ at $19 \mathrm{GHz}$ to $15 \mathrm{~km}$ at $85.5 \mathrm{GHz}$. Detailed SSM/I sensor description can be found in Hollinger $(1989,1991)$. The SSM/I records radiation as Brightness Temperature (Hollinger et al., 1990). Moisture parameters like Total Precipitable Water (TPW), Cloud Liquid Water (CLW) and Rain Rate (RR) can be retrieved from the measured brightness temperature. These parameters with high spatial and temporal variability have a strong influence over the weather forecast. The Radiative Transfer Equation (RTE) required for direct assimilation of brightness temperatures needs a good modeling of the atmospheric state. In the presence of rain the scattering processes become too complex to get correctly reproduced. Because of the 
deficiency, the SSM/I were earlier assimilated mostly through retrieved quantities (Tsuyuki, 1997; Hou et al., 2004; Gerard \& Saunders, 1999). However, the direct radiance assimilation in clear skies and cloudy \& precipitating areas is also operational in many centers. The practical difficulty with passive microwave method over land is the inability in distinguishing the weak "scattering" signature of ice-bearing rain clouds against the highly variable emission from the land surface. Efforts of using 37-GHz observations over land areas (Weinman \& Guetter, 1977; Spencer et al., 1983; Spencer, 1986) have met with partial success. In 1987 with the launch of SSM/I having channels at frequencies higher than $85.5 \mathrm{GHz}$, microwave monitoring of heavier convective rainfall over land became possible (Barrett et al., 1988; Spencer et al., 1989). The major limitation of all passive microwave techniques is their dependence on the brightness temperature depression induced by frozen precipitation aloft. Even due to the presence of few significant ice particles, as often found in orographic and shallow or warm-cloud precipitation, the algorithms may fail to detect the rainfall since the weak $85-\mathrm{GHz}$ scattering signature may be swamped by variations in background emission. Even if detected, rain rates may be significantly underestimated in such cases. Figure 1 shows the rain rate (in $\mathrm{mm} / \mathrm{hr}$ ) captured by SSM/I at $00 \mathrm{UTC}$ of $25^{\text {th }} \mathrm{June}, 2009$. The figures depict the track of the satellite pass and corresponding spatial coverage over the earth. Over Indian region, SSM/I records rain rate at 00 and $12 \mathrm{UTC}$ (figure not included), only.

\section{SSM/I Rain Rate (mm/hr) Spatial Coverage ON 2009062500}

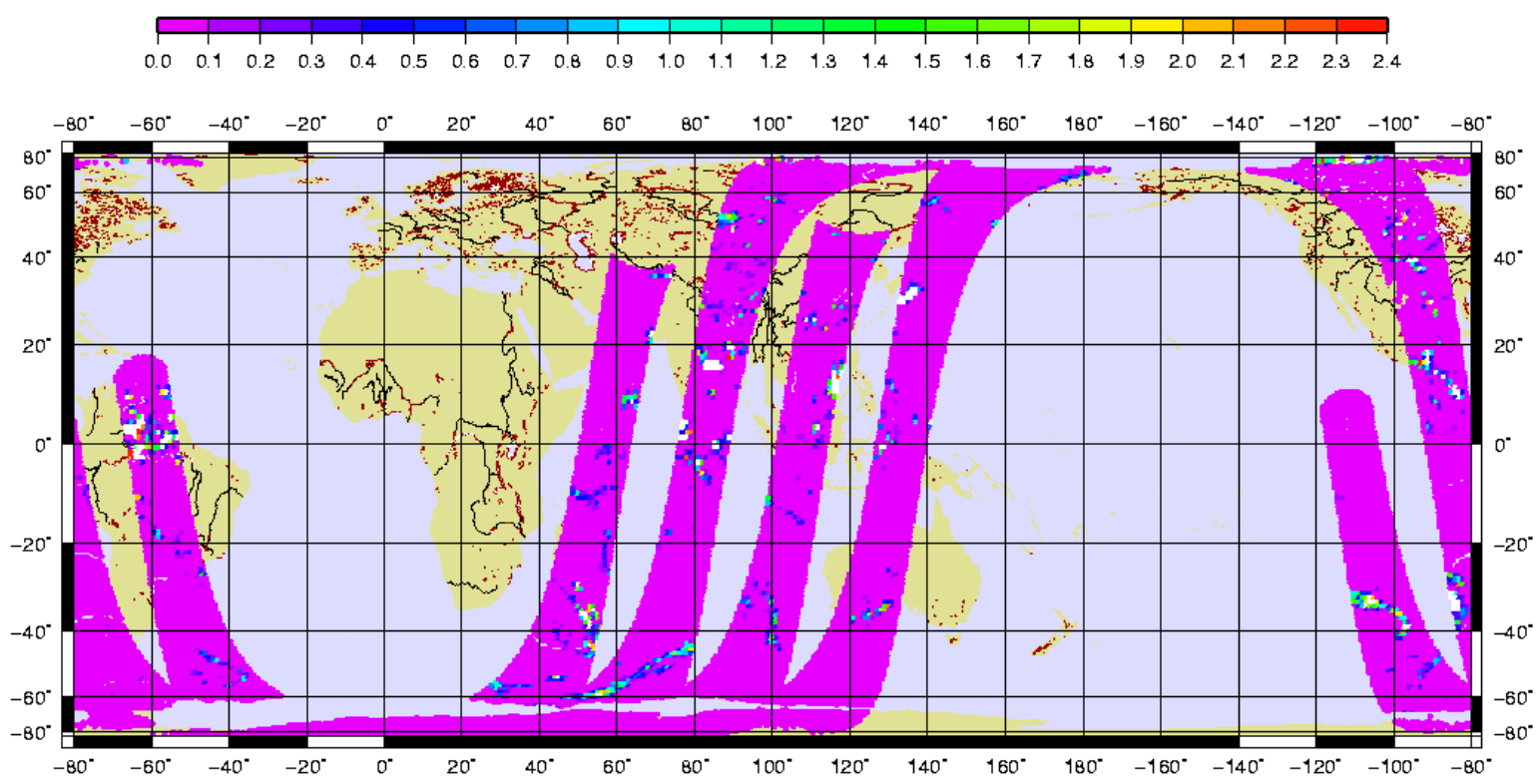

Figure 1. Spatial Coverage of Rain Rate as captured by SSM/I at 00UTC of $25^{\text {th }}$ June 2009

\subsection{TRMM Precipitation Rate}

Under the joint leadership of NASA's Goddard Space Flight Center and National Space Development Agency in Japan, the TRMM (Tropical Rainfall Measuring Mission) satellite project was initiated collaboratively by United States and Japan. The spatial coverage of TRMM spans within $\pm 35^{\circ}$ latitude. It made possible the quantitative measurement of precipitation from space. TRMM comprises of onboard Precipitation Radar (first to be flown in space), a 9-channel passive Microwave Imager (TMI) (like SSM/I), a Visible Infrared Radiometer Sounder (VIRS), a Lightning and a Cloud Sensor (Simpson et al., 1996). The Precipitation Radar, TMI and the VIRS are individually capable of obtaining rainfall, rain type, cloud type, height of the bright band, cloud top height. The TRMM mission and instrument details are available in TRMM home page $\mathrm{http}: / / \mathrm{pmm}$.nasa.gov/TRMM. Figure 2 shows the rain rate (in $\mathrm{mm} / \mathrm{hr}$ ) captured by TRMM at $00 \mathrm{UTC}$ of $25^{\text {th }} \mathrm{June}, 2009$. The figures depict the track of the satellite pass and corresponding spatial coverage over the earth. It is found that over Indian region, TRMM records rain rate at 00,06 and $18 \mathrm{UTC}$ (figures for 06 and $18 \mathrm{UTC}$ not included) only. 


\section{TRMM Rain Rate (mm/hr) Spatial Coverage ON 2009062500}

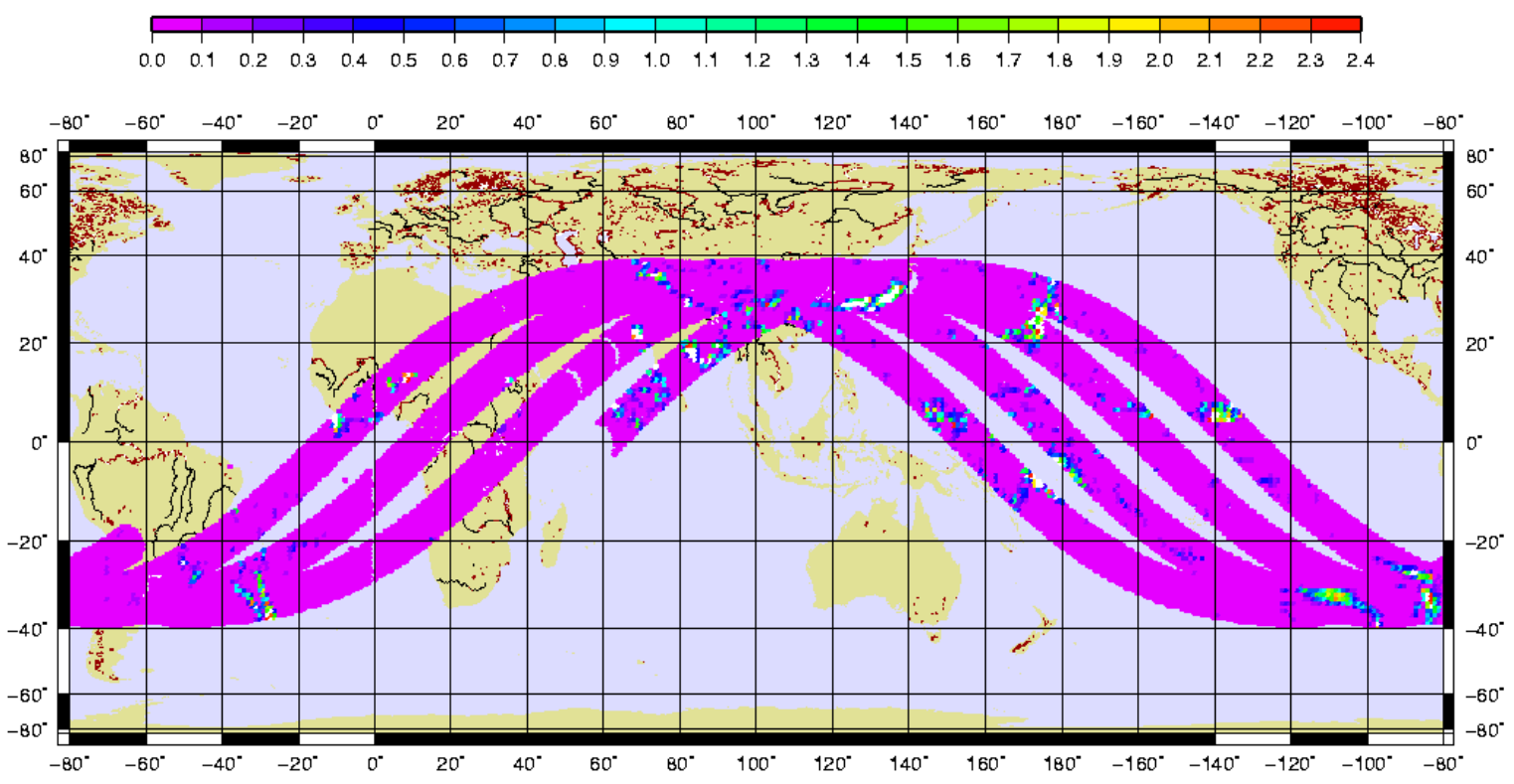

Figure 2. Spatial Coverage of Rain Rate as captured by TRMM at 00UTC of $25^{\text {th }}$ June 2009

\section{Experimental Setup}

\subsection{Model Used}

The Global Data Assimilation and Forecast System (GDAF) used for the study are based on Global Forecast System (GFS) from National Centre for Environmental Prediction (NCEP). GSI scheme for analysis with global model T254L64 is carried out at triangular truncation of wave number 254 with 64 vertical levels. The detailed documentation of GSI and forecast model T254L64 along with the list of observations used in the assimilation system is available in Rajagopal et al. (2007). Analyses are carried out globally for four times daily at six hourly intervals from $00 \mathrm{z}$ to $18 \mathrm{z}$. All the observations that are received at NCMRWF in $+/-3$ hours time window have been used. Model forecasts are carried up to 168 hours. The GSI analysis scheme uses three dimensional variational assimilation techniques. In 3DVar assimilation a cost function is considered and the data is assimilated by minimizing the prescribed cost function through iteration. It uses the tangent linear and adjoint model for computation of gradients of cost function. The cost function consists of two terms; one is the contribution from the observations used and the other is from the background field. The differences in the first guess and the observations are weighted by the observation and the background error covariance matrices, respectively. Since, the precipitation rate measurements are not model analysis variable, so for assimilation of precipitation rate necessary interpolation and transformation from model analysis variables to precipitation rate in the observation locations is required. In GFS the precipitation forecasts are accounted by considering both convective and grid-scale processes. The parameterization of the convective precipitation uses the Simplified Arakawa-Schubert scheme (Grell, 1993) and the grid-scale precipitation processes follow the scheme introduced by Zhao et al. (1997). Using the adjoint models of the precipitation schemes, the observed precipitation is used to adjust the latent heating of the model along with its moisture and cloud water fields.

\subsection{Period of Study}

Monsoon onset over most of the Indian sub-continent takes place in the month of June. The onset dates keep varying from one year to other. This is the month during which the Indian region experiences dry to wet atmospheric conditions, with various monsoon related features getting settled over the place. So, the month of June was selected as the period for the observation system experiment with precipitation rate data. This also gives the scope of extending the simulations for the entire monsoon period. The year chosen is 2009.

\subsection{Monsoon in June, 2009}

During monsoon 2009, though an early onset over Kerala was seen by $23^{\text {rd }}$ May (normal date is $1^{\text {st }}$ June), but there was hiatus in the advance of the monsoon during $8^{\text {th }}-20^{\text {th }}$ June, resulting rainfall only $53 \%$ of Long Period Average in June 2009. Rainfall activity subsequently increased in later part of June. Main monsoon systems like monsoon 
trough, cross equatorial trough, north-south surface pressure gradient, etc. were comparatively weak throughout the month, resulting in below normal rainfall over India. In June, two depressions were formed. The depression over east central Arabian Sea moved northwards along the west coast and weakened after crossing the south Gujarat coast during 23-24 June. The remnant of this system re-emerged over the northeast Arabian Sea and concentrating again into a depression moved northwards over the land during 25-26 June and weakened over Kutch and neighborhood. This depression was accompanied by rainfall of about $16-32 \mathrm{~cm}$. over the surrounding region.

\subsection{Experiment}

Two sets of simulations were performed. In the first set of simulation, precipitation rate measured by SSM/I and TRMM are assimilated and subsequent $168 \mathrm{hr}$ forecasts are made through the NCMRWF's GFS for the entire month of June-2009. In the second set, the analyses and forecasts are also repeated for the entire period without the assimilation of precipitation rate data.

The basic set of observations used in the assimilation system as documented by Rajagopal et al. (2007) and the model setup remains the same for both types of simulations. Henceforth, the simulations without precipitation assimilation will be termed as "CTRL" and those with precipitation rate assimilation will be termed as "EXP".

\section{Results and Discussions}

For the present observation system experiment, Northern and Southern Hemisphere, Tropics $\left(30^{\circ} \mathrm{S}\right.$ to $\left.30^{\circ} \mathrm{N}\right)$ and Indian Region $\left(10^{\circ} \mathrm{S}\right.$ to $40^{\circ} \mathrm{N}, 40^{\circ}$ to $\left.100^{\circ} \mathrm{E}\right)$ have been studied in detail. Giving special emphasis to the Indian Summer Monsoon, the discussions are confined over Tropics and Indian region. The discussions of the results over the regions are grouped into Analysis vs. Observation, Forecast vs. Observation, and Forecast vs. Analysis. The scores over the respective regions are the values averaged in space and time. $850 \mathrm{hPa}$ pressure level is considered to represent lower troposphere, $500 \mathrm{hPa}$ the mid-troposphere and $250 / 200 \mathrm{hPa}$ the upper troposphere.

For determining the direct and first hand information of the models acceptance of the new data type assimilated, the difference of the temperature (Figure 3) and specific humidity (Figure 4) fields at $850 \mathrm{hPa}$ from the two analyses (EXP \& CTRL) are computed against their respective first guess, after the first assimilation cycle. The precipitation data is found to have more impact over temperature compared to that over specific humidity. Perhaps, the differences in the difference plots are observed mainly over the regions of the satellite pass at that assimilation hour.

\section{Temperature Difference - $850 h P \alpha$ (Analysis - First Guess):First Cycle}
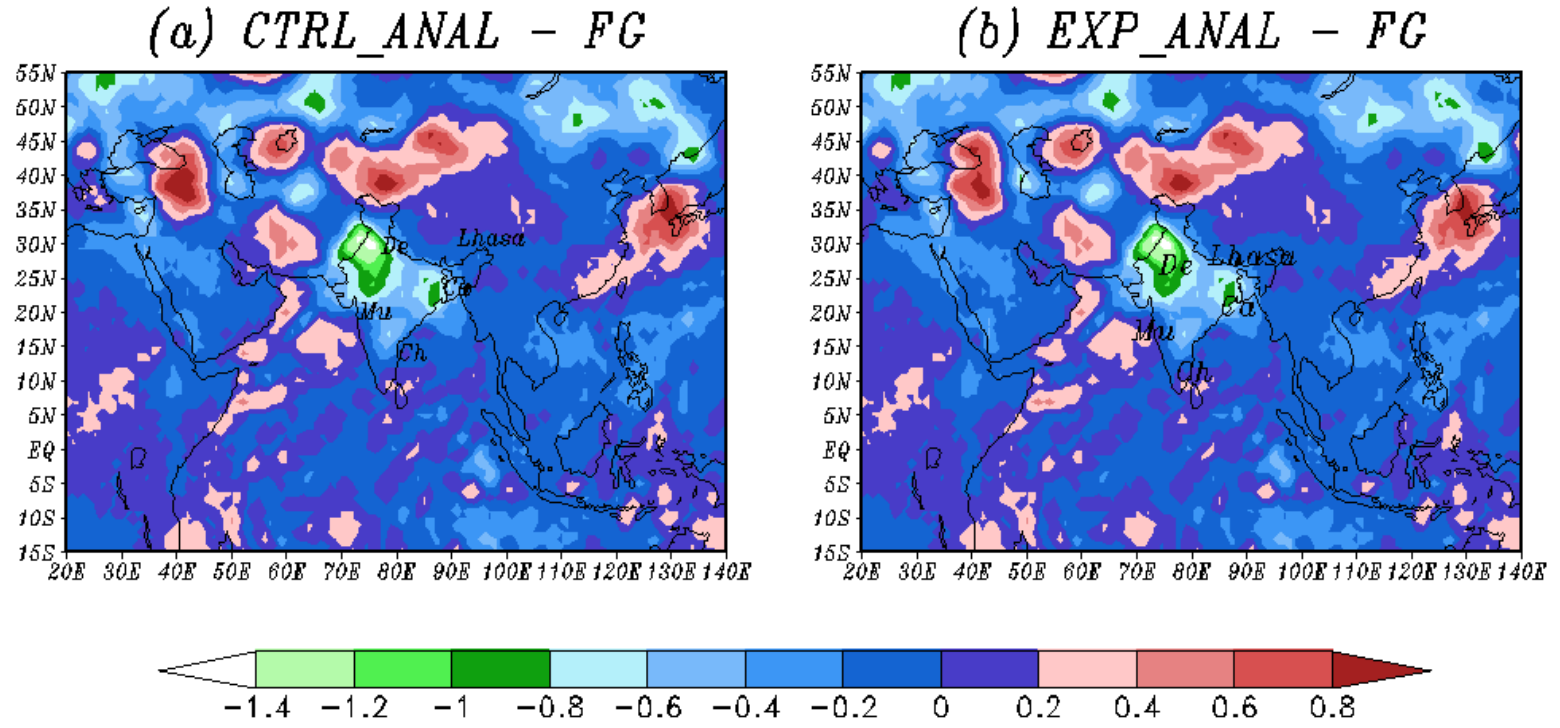

Figure 3. Temperature difference at $850 \mathrm{hPa}$ between the (a) Control analysis \& (b) Experimental analysis from their respective first guess after the first assimilation cycle 


\section{Specific Humidity $(\mathrm{gm} / \mathrm{kg})$ Difference - 850hPa (Analysis - First Guess):First Cycle}
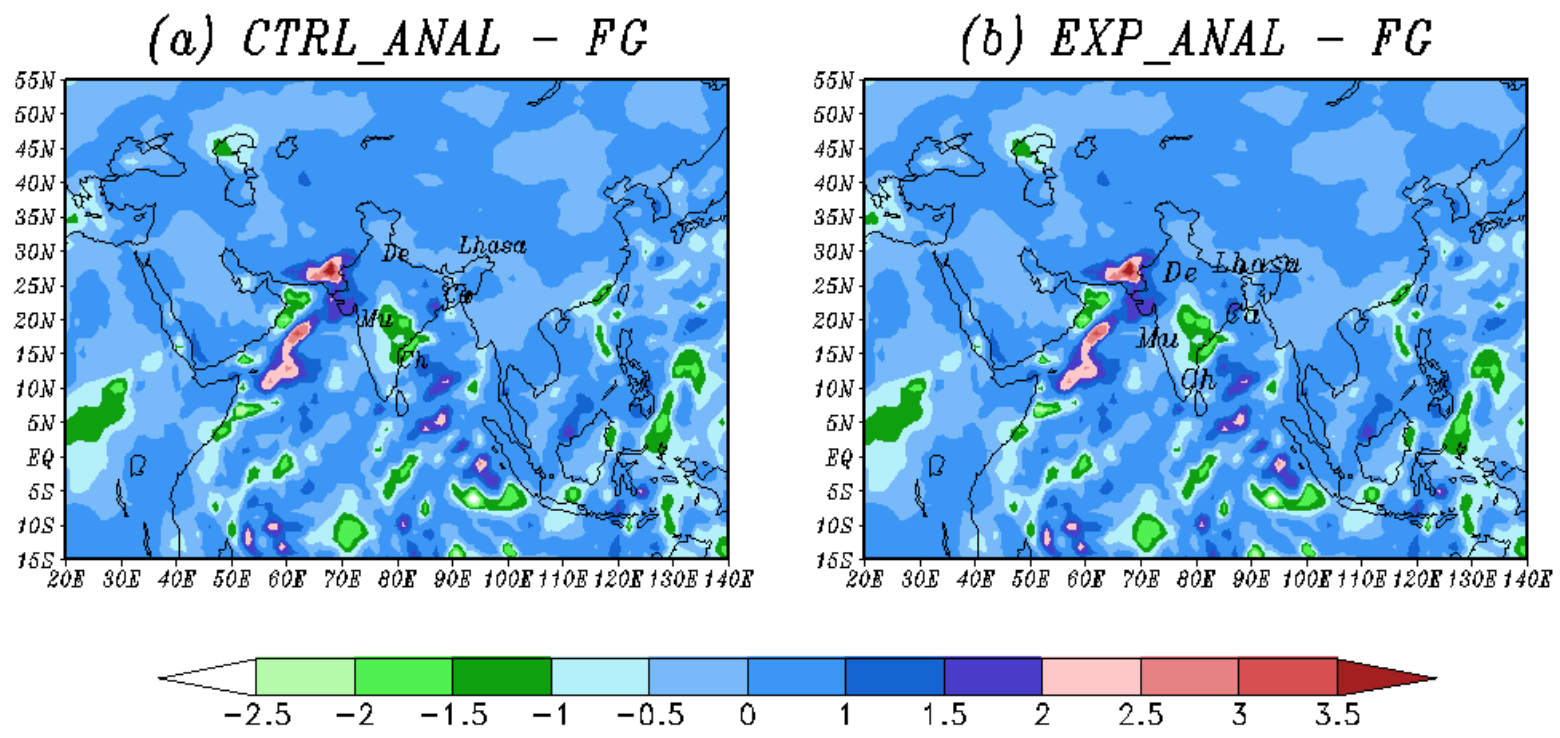

Figure 4. Specific Humidity $(\mathrm{gm} / \mathrm{kg}$ ) difference at $850 \mathrm{hPa}$ between the (a) Control analysis \& (b) Experimental analysis from their respective first guess after the first assimilation cycle

Analyses from the control and experiment simulations were compared with the observations (Analysis vs. Observation study) generally the radiosonde observations over the region. The RMSE (Root Mean Square Error) of geo-potential height, temperature and vector wind are computed at the observation location and averaged over the region of study. Figures 5 and 6 displays the geo-potential height, temperature and vector wind (analyses variables) RMSE with respect to the observations over the Tropics and Indian region, respectively. Improvement in terms of lower RMSE is observed both over Tropics and Indian region. Positive impact on temperature (Figure $5 \mathrm{~b} \& 6 \mathrm{~b}$ ) is seen over all the three levels of 850,500 and $250 \mathrm{hPa}$. For vector wind (Figure $5 \mathrm{c} \& 6 \mathrm{c}$ ) and geo-potential height (Figure 5a \& 6a) positive impact of assimilation is seen over 500 and $250 \mathrm{hPa}$ pressure levels. Other than for RMSE of vector wind over Indian region, for all other cases, RMSE is found to be highest at $250 \mathrm{hPa}$ pressure level and mostly lowest at $850 \mathrm{hPa}$. The positive effect of precipitation rate assimilation is seen throughout the atmosphere. Temperature and wind are two of the important parameters whose spatial distribution directly affects the humidity and in turn the precipitation gets affected. The analyses vs. observation study have highlighted the positive effect of precipitation rate assimilation on the analyses over the Tropics and Indian region. The RMSE values being area averaged over wide regions, their differences between the two simulations are found to be quantitatively small. Daily observation data counts in hundreds over tropics and Indian region that have been used for computing the RMSE score of analyses vs. observation has been depicted in Figures 7 and 8, respectively. Over both tropics and Indian region the data count has reduced in the latter half of the month over all the three levels. Maximum number of observations is found at $500 \mathrm{hPa}$ pressure level. Data counts ranges from about 50 to 4800 . 

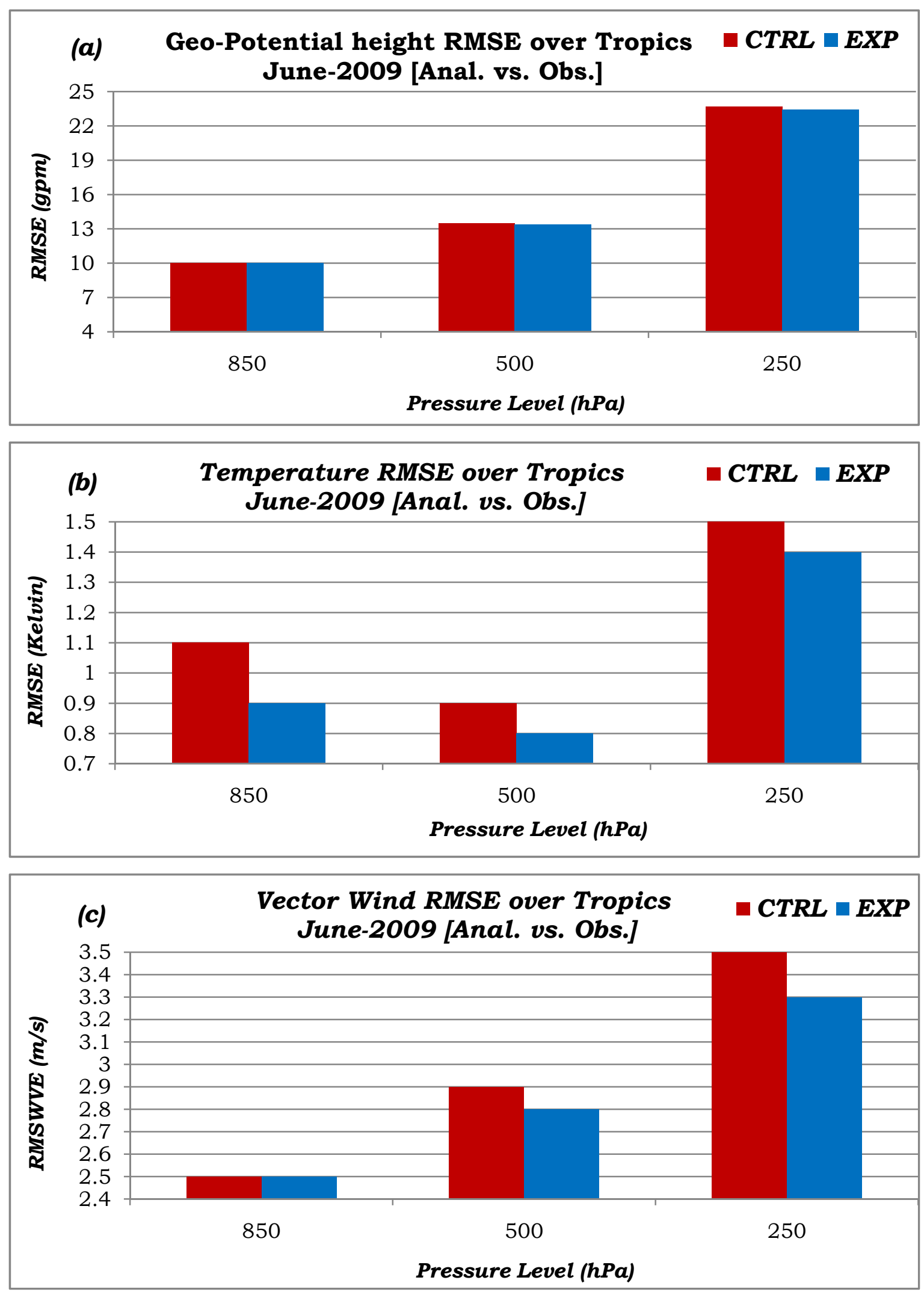

Figure 5. Root Mean Square Error of Analyses with respect to Observations over Tropics for June-2009 for (a) Geo-Potential Height, (b) Temperature \& (c) Vector Wind 

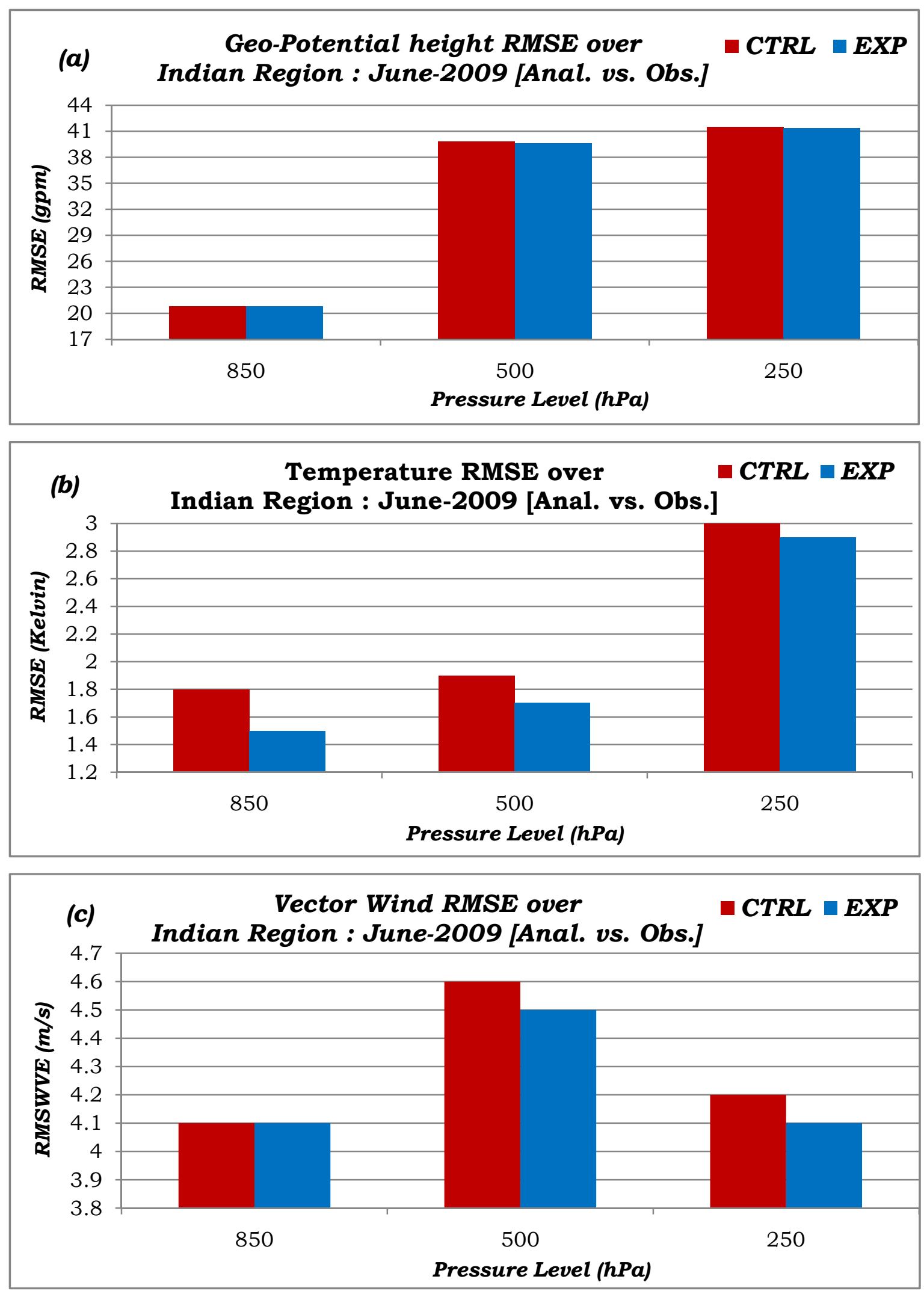

Figure 6. Root Mean Square Error of Analyses with respect to Observations over Indian Region for June-2009 for (a) Geo-Potential Height, (b) Temperature \& (c) Vector Wind 


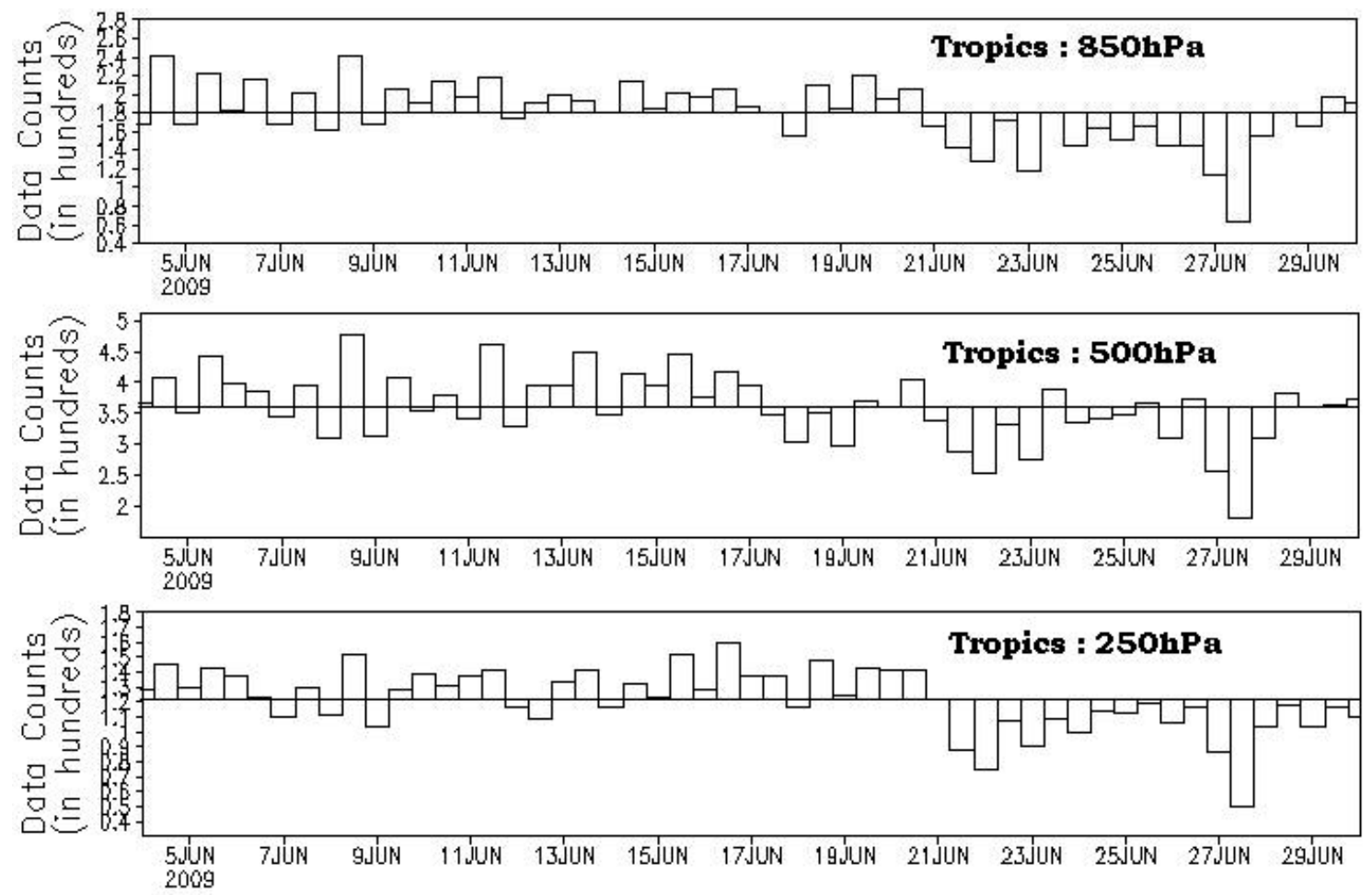

Figure 7. Observation Data Counts in Hundreds over Tropics used for computing the RMSE of Analyses vs. Observation at 850,500 and $250 \mathrm{hPa}$ pressure levels
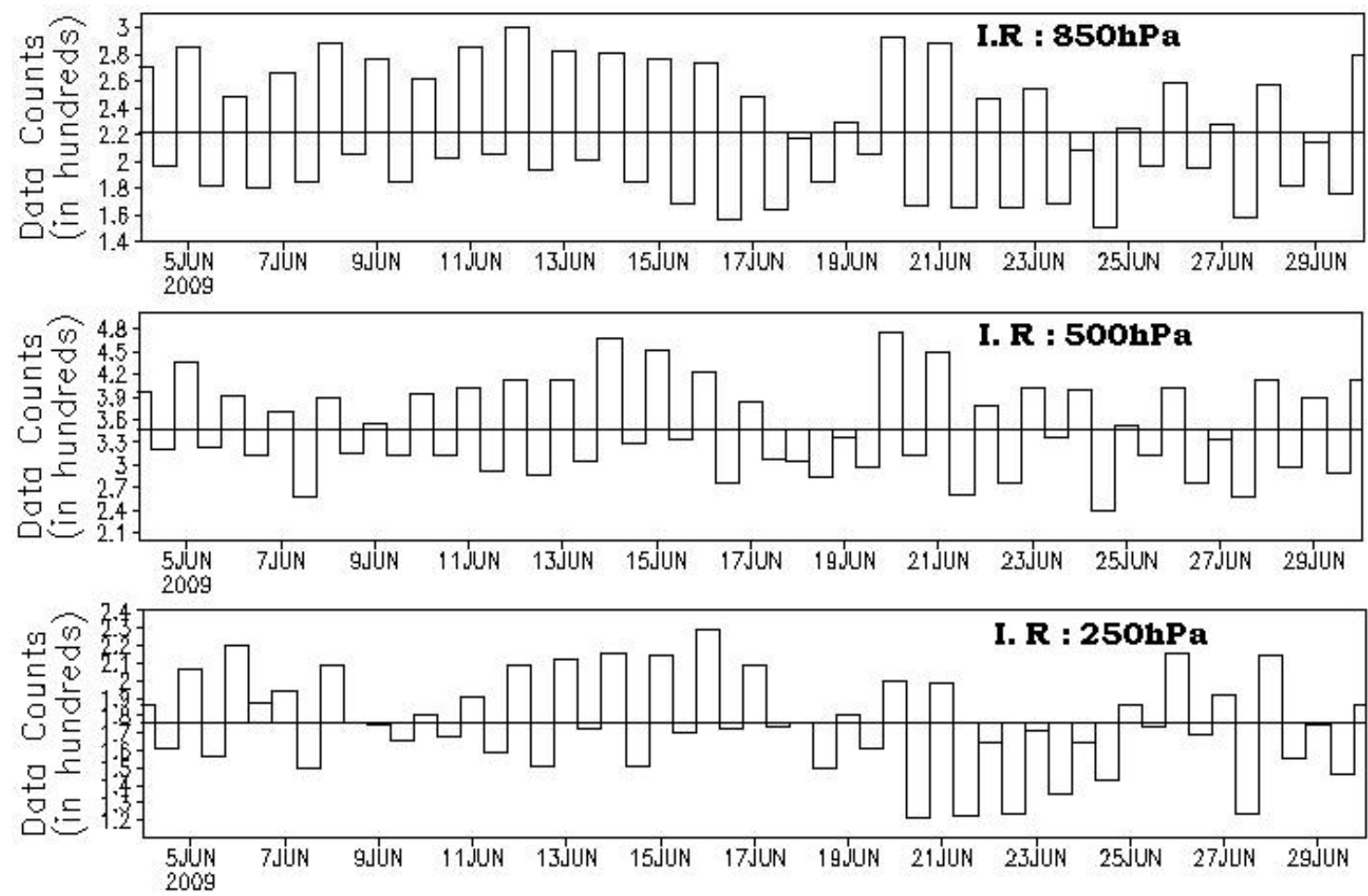

Figure 8. Observation Data Counts in Hundreds over Indian Region (I.R) used for computing the RMSE of Analyses vs. Observation at 850, 500 and 250hPa pressure levels 
Improvement in analyses is followed by the improvement in forecast. For the impact over the forecast simulation, forecasts are first compared with the respective analyses (Forecast vs. Analysis study). Forecast vs. Analysis comparisons are made in terms of anomaly correlation (AC), pattern correlation (PC) and root mean square error (figures not included). Though in some cases the scores for the experimental runs were better, significant and consistent improvement over the control runs was not observed.

Next, to further evaluate the improvement in forecast, the day 1 to day 7 forecasts from the two simulations are compared with the observations (mainly the radiosonde observations available) and the RMSE of temperature, vector wind and geo-potential height are computed at 850, 500 and 250hPa pressure level. The corresponding values are area averaged over the region of interest. Figure 9 provides the temperature RMSE over Tropics (a, b \&c) and over the Indian region (d, e \& f) at 850,500 and $250 \mathrm{hPa}$ pressure levels for the forecasts from the two simulations with respect to the observations. Consistent improvement in terms of lower RMSE is found over both Tropics and Indian region. At $850 \mathrm{hPa}$, the experimental forecasts have lower temperature RMSE for day 1 to day 4 over tropics and day 1 to day 3 over Indian region. At 500hPa, "EXP" forecasts have lower temperature RMSE for forecasts valid at day 1, day 2 and day 4, over both the regions. But at 250hPa, the "EXP" has lower RMSE only at day $1 \&$ day 3 forecasts over tropics and day $1 \&$ day 4 forecasts over Indian region. For the other days over the three levels, the RMSE are either equal or very close to each other. Improvement in vector wind and geo-potential forecasts is also observed. At $850 \mathrm{hPa}$, experimental simulations over Tropics have lower vector wind RMSE for forecasts valid at day $1 \&$ day 2 and for forecasts valid at day $3 \&$ day 4 over Indian region (Figure 10 a \& d). At $500 \mathrm{hPa}$ pressure level (Figure $10 \mathrm{~b} \& \mathrm{e}$ ), improvement over Tropics and Indian region is seen for all the days of forecast except for day 4 over Indian region, where the RMSE from both the simulations are equal. Over Indian region at 250hPa, vector wind RMSE of "EXP" forecasts have lower RMSE at day 1 to day 4 (Figure 10f) whereas over Tropics "EXP" have lower RMSE only at day 1 \& day 5 (Figure 10c). For other days, the RMSE's are equal. RMSE plots for geo-potential height are presented in Figure 11. At $850 \mathrm{hPa}$, "EXP" simulations have lower geo-potential RMSE for forecasts valid for all the days over Tropics and Indian region (Figure 11 a \& d). Except for day 5 forecast over Indian region where the geo-potential RMSE's are equal for both the simulations, the "EXP" forecasts have lower geo-potential height RMSE at 500hPa over both Tropics and Indian region (Figure $11 \mathrm{~b} \& \mathrm{e}$ ). At $250 \mathrm{hPa}$, "EXP" forecasts have lower geo-potential height RMSE for day 1 to day 3 whereas over tropics the improvement is observed for all the days of forecast (Figure $11 \mathrm{c} \& \mathrm{f}$ ). The daily observation data counts used for forecast vs. observation study are same to that depicted in Figures $7 \& 8$.
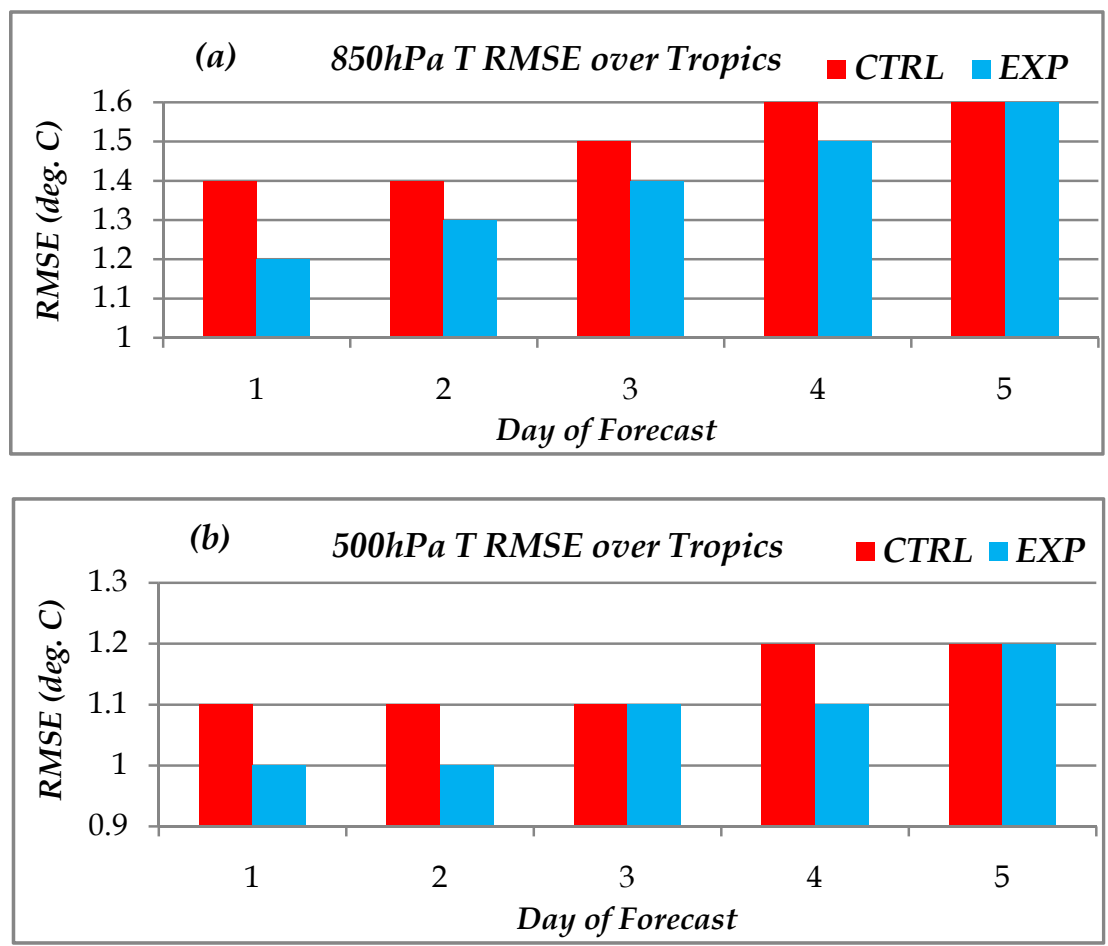

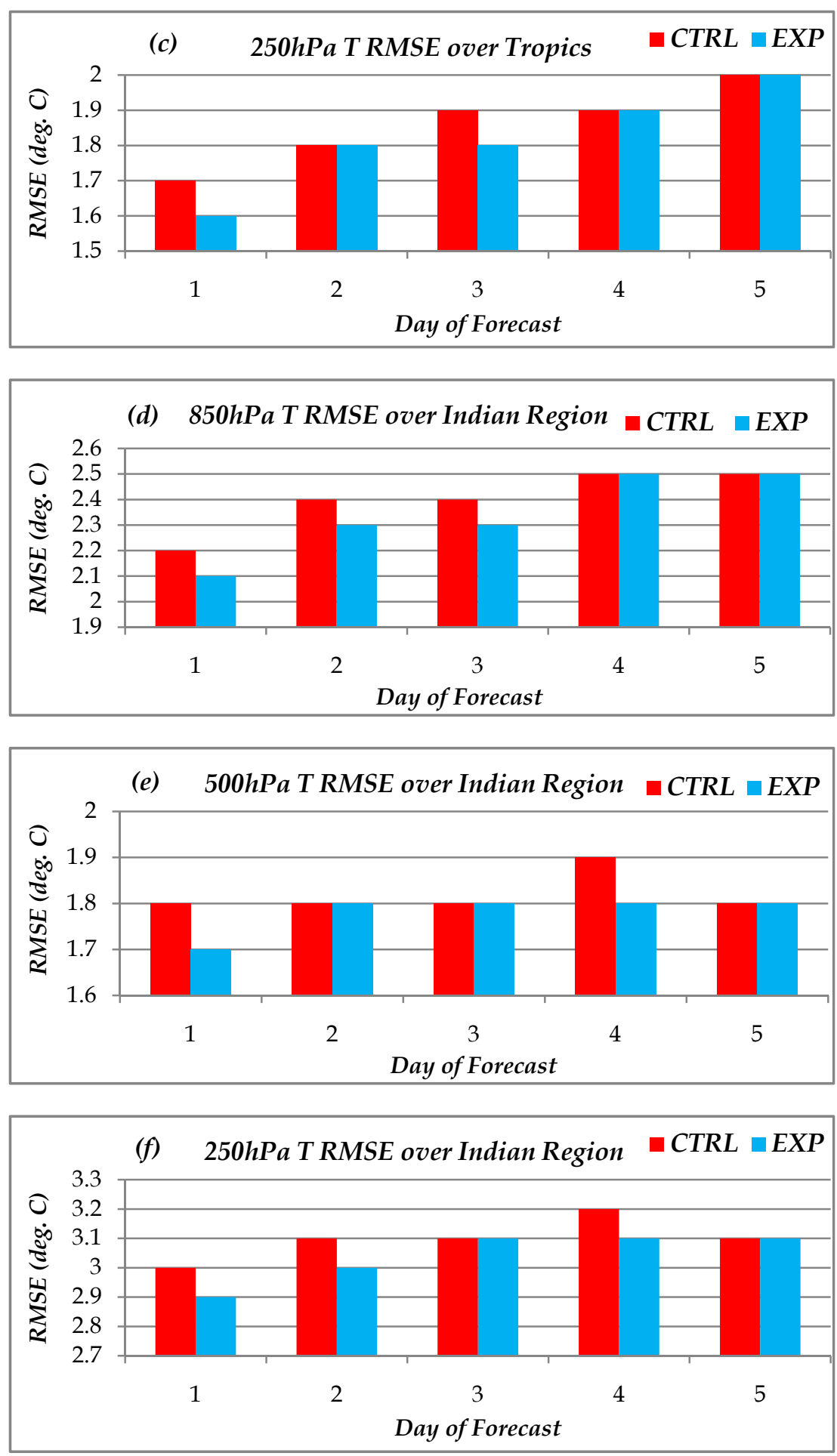

Figure 9. Temperature RMSE over Tropics (a, b \&c) and over Indian region (d, e \& f) at 850, 500 and 250hPa pressure levels for the forecasts using control and experimental analyses with respect to the observations 

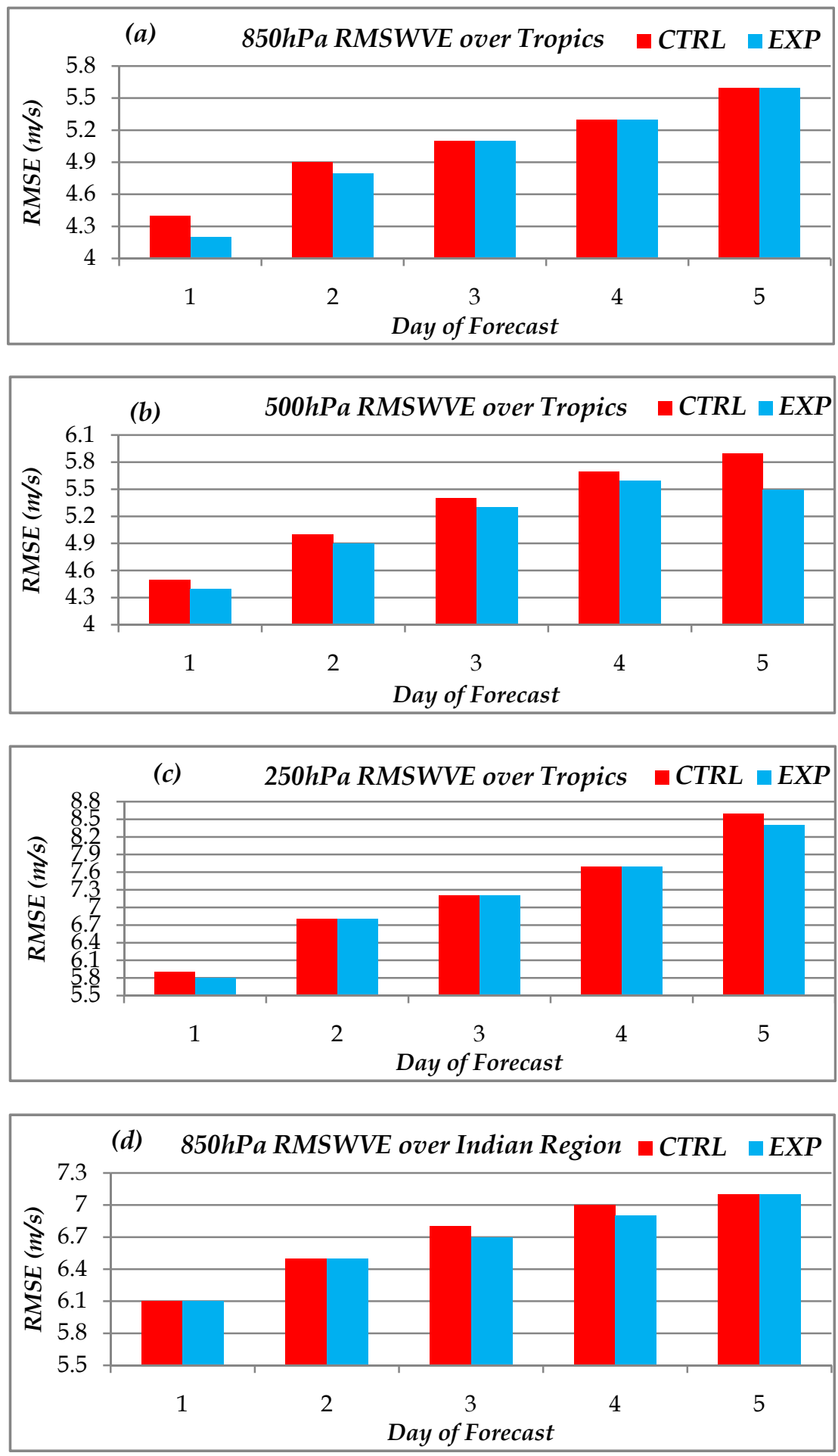

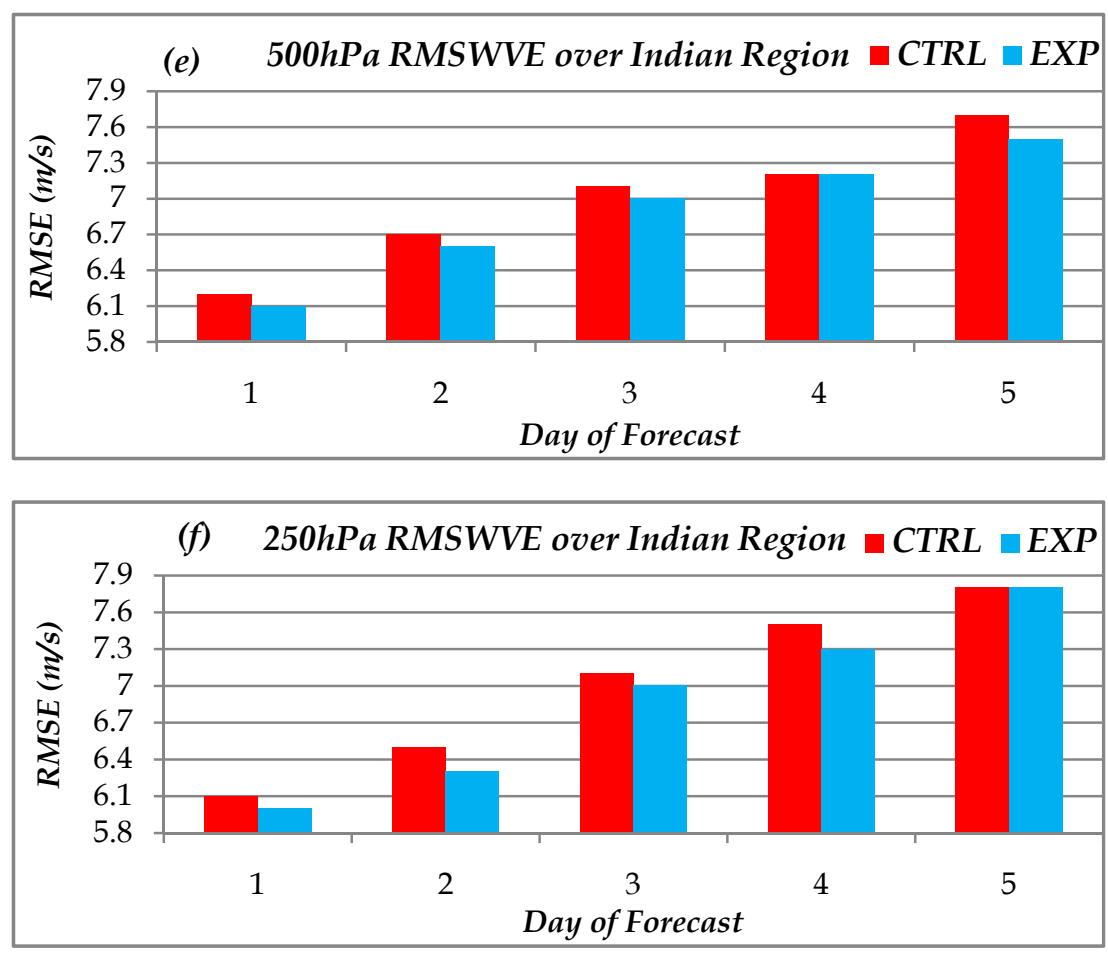

Figure 10. Same as Figure 9 but for Vector Wind
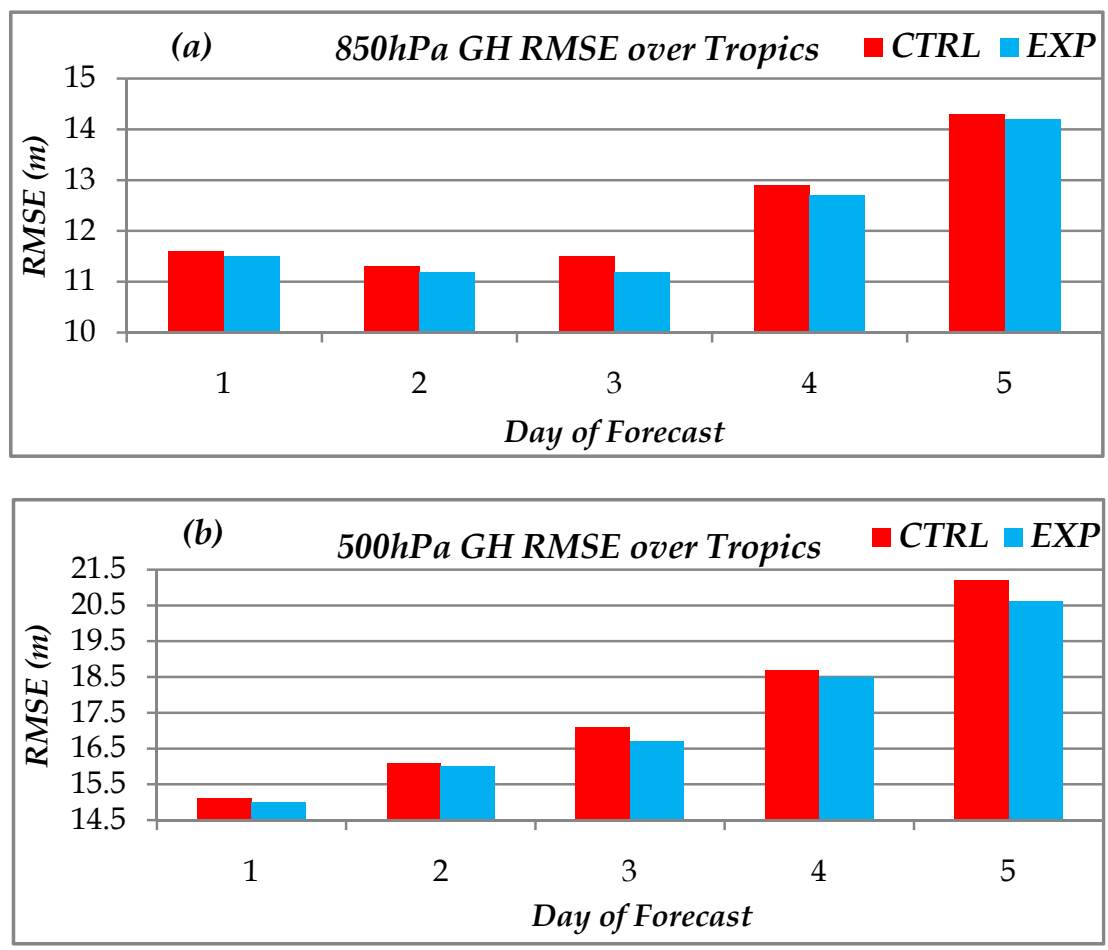

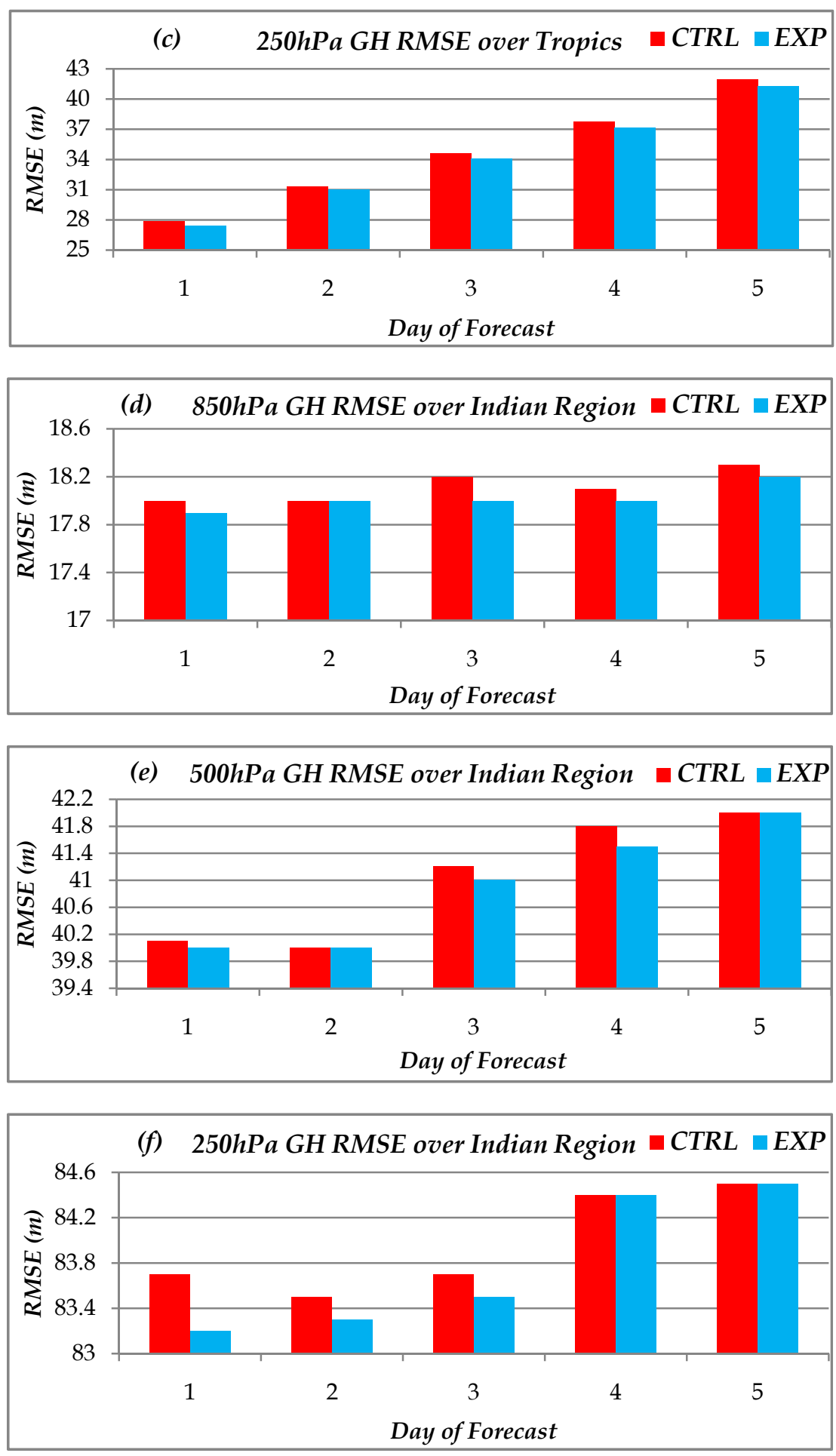

Figure 11. Same as Figure 9 but for Geo-Potential Height

A new data type when assimilated in a NWP model incorporates biases. For studying the impact of such biases between the model and the observation, the mean differences (EXP-CTRL) in precipitation (Figure 12), and humidity (Figure 13) and temperature (Figure 14) at $850 \mathrm{hPa}$ pressure level are plotted. Figure 13 presents the difference in mean rainfall for the month of june-2009 between experimental and control forecasts valid at day-1, day-3 and day-5. It is observed that the difference increases with the days of forecasts. The difference of about 0.4-0.6 cm in the Arabian Sea coast for Day-3 forecasts has shifted to the western coasts of India for Day-5 
forecasts. With increase in the rainfall difference, the models show corresponding increase in specific humidity (Figure 13) and decrease in temperature (Figure 14) with the forecasts days, especially over the western coast of India. With the advance of forecast days, the experimental forecasts have dissipated more rainfall over central to western peninsular India, resulting in corresponding increase in specific humidity and decrease in temperature at $850 \mathrm{hPa}$ pressure level. This has resulted in increasing the forecast value of specific humidity and decreasing the same for temperature at $850 \mathrm{hPa}$ pressure level over the concerned regions. The analyses difference for specific humidity and temperature are also contrasting.

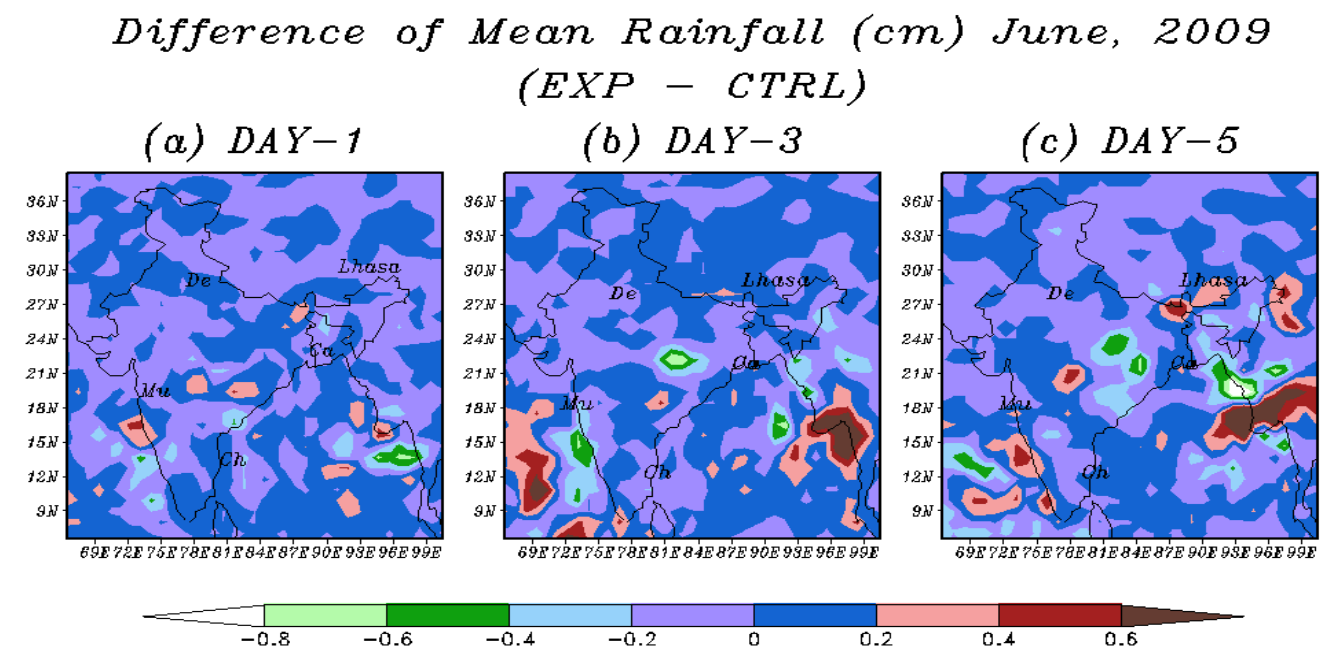

Figure 12. Difference of Mean Rainfall (cm) [EXP - CTRL] for the month of June-2009 for the forecasts valid at (a) Day-1, (b) Day-3 and (c) Day-5
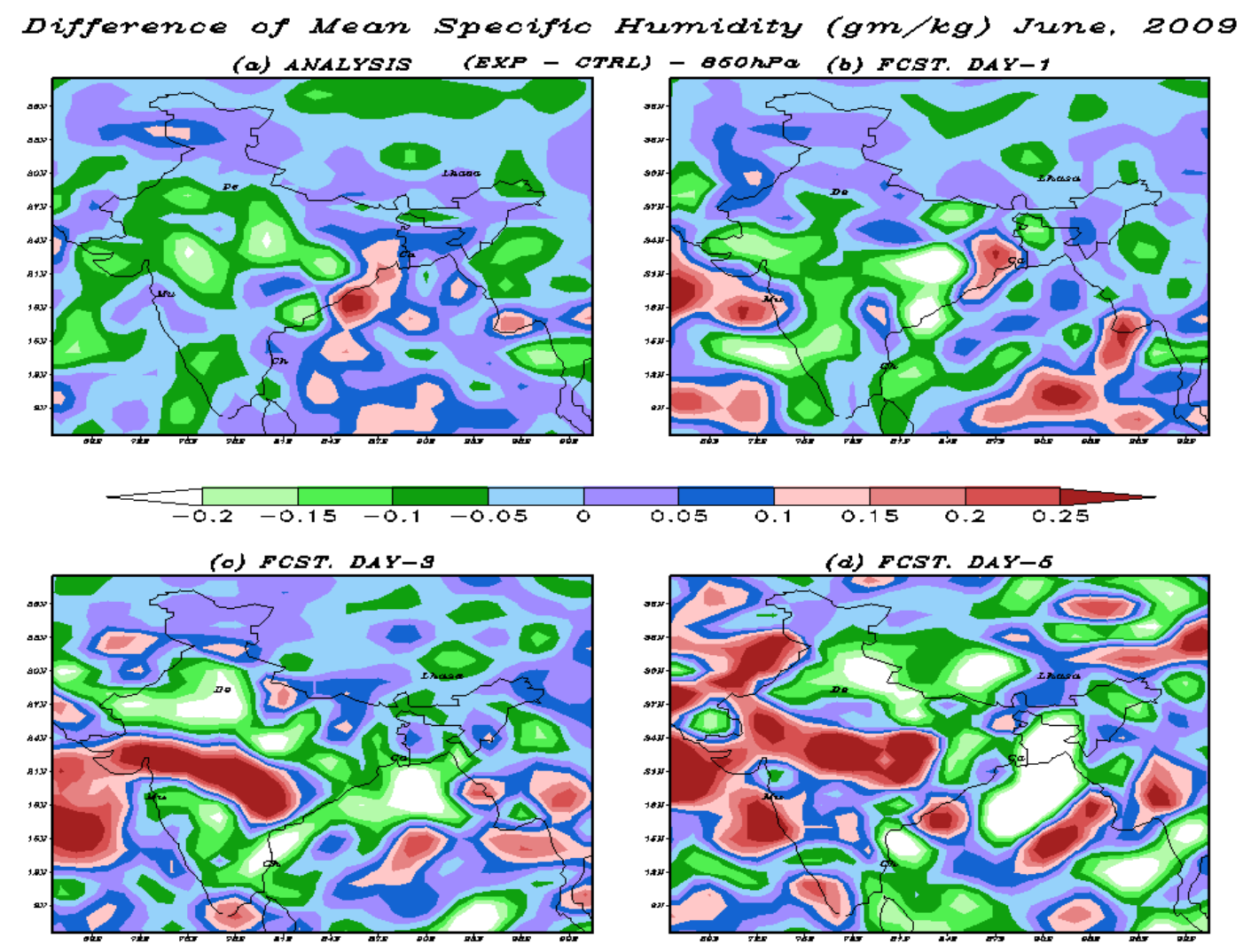

Figure 13. Difference of Mean Specific Humidity (gm/kg) [EXP - CTRL] for the month of June-2009 for the (a) analysis and forecasts valid at (b) Day-1, (c) Day-3 and (d) Day-5 

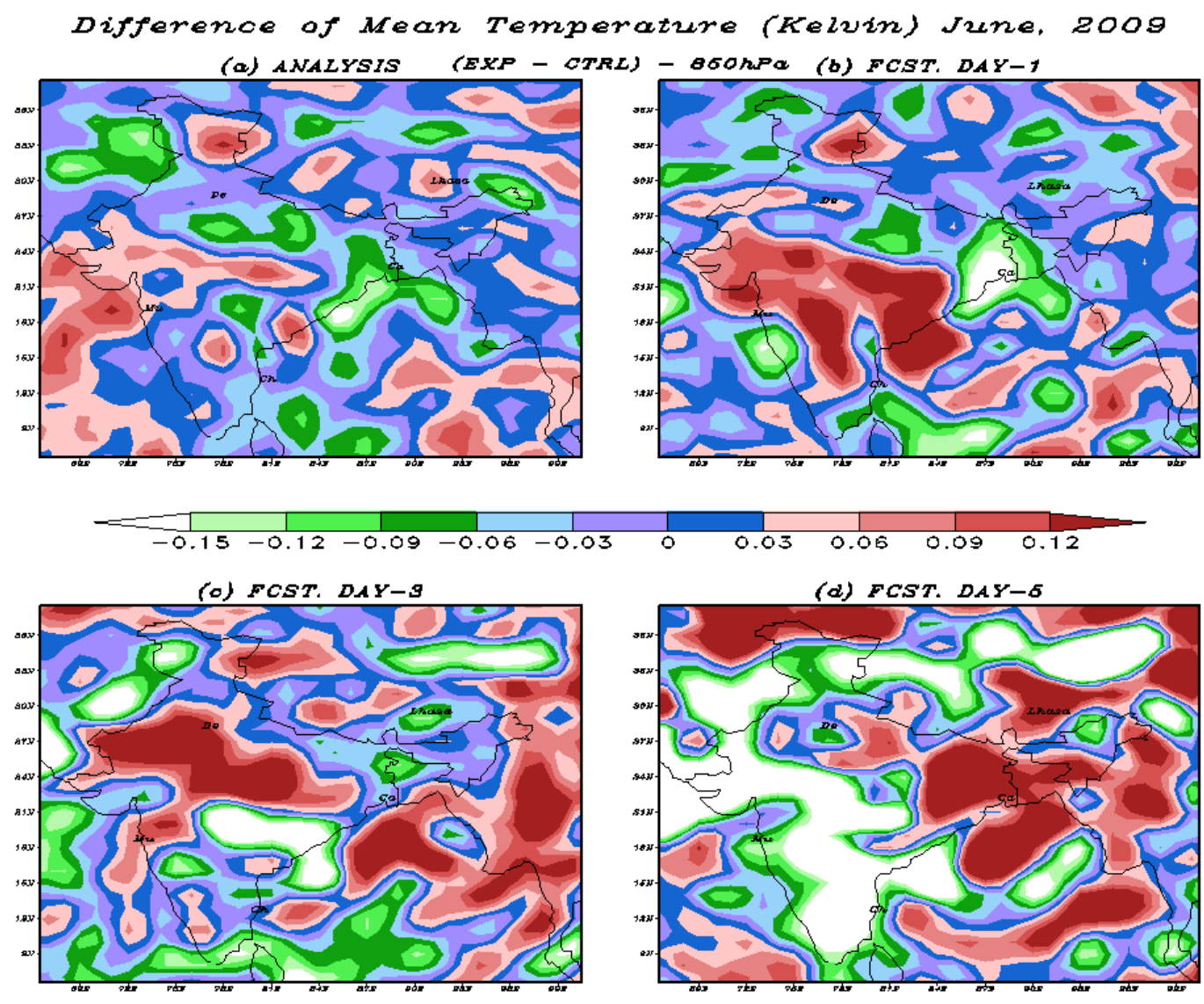

Figure 14. Difference of Mean Temperature (Kelvin) [EXP - CTRL] for the month of June-2009 for the (a) analysis and forecasts valid at (b) Day-1, (c) Day-3 and (d) Day-5

\section{Conclusions}

The present study examines the combined impact of precipitation rate data recorded by SSM/I onboard the DMSP satellites and those obtained from the TRMM over India and surrounding regions. Improvement on the analysis and forecast from experimental simulations was found when compared with the observations. Forecast versus respective analysis didn't show significant difference. The results obtained in the present study are summarized below.

1) Analysis when compared with observations, improvement in terms of lower RMSE is observed both over Tropics and Indian region. Positive impact on temperature is seen over all the three levels of 850, 500 and $250 \mathrm{hPa}$. For vector wind and geo-potential height positive impact of assimilation is seen over 500 and 250hPa pressure levels.

2) For forecast versus analysis comparison, the differences in the values from the two simulations are mostly insignificant. For few cases, the experimental simulations shows significant improvement over the control runs.

3) Consistent improvement in the experimental forecast in terms of lower RMSE is found over both Tropics and Indian region, when compared with the observations. Improvement in all the three parameters (temperature, horizontal wind and geo-potential height) is observed. RMSE's observed are either lower for the experimental forecast or are equal compared to the control forecasts.

4) The present study is intended to study the model response towards the precipitation rate data. India has recently launched satellite MEGHA-TROPIQUES which is a part of Global Precipitation Measurement (GPM) mission. With high technology sensors onboard, it will provide voluminous measurements of humidity in all its form. This study will help us to conduct a similar and more sensitive experiments with the data obtained from the satellite MEGHA-TROPIQUES. 


\section{Acknowledgement}

The authors gratefully acknowledge NCEP for sharing the GDAFS code. The authors are also thankful to Director, NCMRWF for her encouragement and support by providing the necessary facilities to carry out this research work.

\section{Reference}

Alpert, J. C., Hong, S. Y., \& Kim, Y. J. (1996). Sensitivity of cyclogenesis to lower troposphere enhancement of gravity wave drag using the Environmental Modeling Center medium range model. In Proceedings of $11^{\text {th }}$ Conference on NWP, Norfolk; 322-323.

Asselin, R. (1972). Frequency filter for time integrations. Monthly Weather Review, 100, 487-490. http://dx.doi.org/10.1175/1520-0493(1972)100<0487:FFFTI $2.3 . C O ; 2$

Barrett, E. C., Kidd, C., \& Bailey, J. O. (1988). The Special Sensor Microwave/Imager: A new instrument with rainfall monitoring potential. International Journal of Remote Sensing, 9, 1943-1950. http://dx.doi.org/10.1080/01431168808954993

Basu, S., Ramesh, K. J., \& Begum, Z. N. (1999). Medium range prediction of summer monsoon activities over India vis-á-vis their correspondence with the observational features. Advances in Atmospheric Science, 16(1), 133-146. http://dx.doi.org/10.1007/s00376-999-0009-0

Charnock, H. (1955). Wind stress on a water surface. Quarterly Journal of Royal Meteorological Society, 81, 639-640. http://dx.doi.org/10.1002/qj.49708135027

Chevallier, F., Bauer, P., Mahfouf, J. F., \& Morcrette, J. J. (2002). Variational retrieval of cloud profile from ATOVS observations. Quarterly Journal of Royal Meteorological Society, 128, 2511-2526. http://dx.doi.org/10.1256/qj.01.153

Donner, L. J. (1988). An initialization for cumulus convection in numerical weather prediction models. Monthly Weather Review, 116, 377-385. http://dx.doi.org/10.1175/1520-0493(1988)116<0377:AIFCCI >2.0.CO;2

Fiorino, M, \& Warner, T. T. (1981). Incorporating surface winds and rainfall rates into the initialization of a mesoscale hurricane model. Monthly Weather Review, 109, 1914-1929. http://dx.doi.org/10.1175/1520-0493(1981)109<1914:ISWARR >2.0.CO;2

Gelaro, R., Langland, R. H., Pellerin, S., \& Ricardo, T. (2010). The THORPEX Observation Impact Intercomparison Experiment. Monthly Weather Review, 138, 4009-4025. http://dx.doi.org/10.1175/2010MWR3393.1

Gerard, E., \& Saunders, R. (1999). Four-dimensional variational assimilation of Special Sensor Microwave/Imager total column water vapour in the ECMWF model. Quarterly Journal of Royal Meteorological Society, 125, 1453-1468. http://dx.doi.org/10.1256/smsqj.56013

Grell, G. A. (1993). Prognostic Evaluation of Assumptions Used by Cumulus Parameterizations. Monthly Weather Review, 121, 764-787. http://dx.doi.org/10.1175/1520-0493(1993)121<0764:PEOAUB >2.0.CO;2

Heckley, W. A., Kelly, G., \& Tiedtke, M. (1990). On the use of satellite derived heating rates for data assimilation within the tropics. Monthly Weather Review, 118, 1743-1757. http://dx.doi.org/10.1175/1520-0493(1990)118<1743:OTUOSD >2.0.CO;2

Hollinger, J., Peirce, J., \& Poe, G. (1990). SSM/I Instrument Evaluation. IEEE Trans. Geosci. Remote Sens., 28 , 781-790. http://dx.doi.org/10.1109/36.58964

Hollinger, J. P. (1989). DMSP Special Sensor Microwave/Imager calibration/validation. In Final Report Vol. I, [Available from the author at Naval Research Laboratory, Washington, D.C. 20375.]

Hollinger, J. P. (1991). DMSP Special Sensor Microwave/Imager calibration/validation. In Final Report Vol. II, [Available from the author at Naval Research Laboratory, Washington, D. C. 20375.]

Hong, S. Y., \& Pan, H. L. (1996). Nonlocal boundary layer vertical diffusion in a medium range forecast model. Monthly Weather Review, 2322-2339. http://dx.doi.org/10.1175/1520-0493(1996)124<2322:NBLVDI>2.0.CO;2

Hou, A., Zhang, S., \& Reale, O. (2004). Variational Continuous assimilation of TMI and SSM/I Rain Rates: Impact on GOES-3 Hurricane Analyses and Forecasts. Monthly Weather Review, 132, 2094-2109. http://dx.doi.org/10.1175/1520-0493(2004)132<2094:VCAOTA>2.0.CO;2

Hou, Y. T., Campana, K. A., \& Yang, S. K. (1996). Shortwave radiation calculations in the NCEP's global model. In International Radiation Symposium, IRS-96, August 19-24, Fairbanks, AL. 
Janisková, M., Mahfouf, J. F., \& Morcrette, J. J. (2002). Preliminary studies on the variational assimilation of cloud radiation observations. Quaterly Journal of Royal Meteorological Society, 128, 2713-2736. http://dx.doi.org/10.1256/qj.01.192

Jones, C. D., \& Macpherson, B. (1997). A latent heat nudging scheme for the assimilation of precipitation data into an operational mesoscale model. Meteorological Applications, 4, 269-277. http://dx.doi.org/10.1017/S1350482797000522

Kalnay, E., Kanamitsu, M., \& Baker, W. E. (1990). Global numerical weather prediction at the National Meteorological Center. Bulletin of American Meteorological Society, 71, 1410-1428. http://dx.doi.org/10.1175/1520-0477(1990)071<1410:GNWPAT>2.0.CO;2

Kanamitsu, M., Alpert, J. C., Campana, K. A., Caplan, P. M., Deaven, D. G., Iredell, M., ... White, G. H. (1991). Recent changes implemented into the global forecast system at NMC. Weather and Forecasting, 6, 425-435. http://dx.doi.org/10.1175/1520-0434(1991)006<0425:RCIITG >2.0.CO;2

Kanamitsu, M. (1989). Description of the NMC global data assimilation and forecast system. Weather and Forecasting, 4, 335-342. http://dx.doi.org/10.1175/1520-0434(1989)004<0335:DOTNGD >2.0.CO;2

Kasahara, A., Mizzi, A. P., \& Donner, L. J. (1994). Diabatic initialization for improvement in the tropical analysis of divergence and moisture using satellite radiometric imagery data. Tellus, 46A, 242-264.

Krishnamurti, T. N., Bedi, H. S., \& Ingles, K. (1993). Physical initialization using SSM/I rain rates. Tellus, 45A, 247-269.

Krishnamurti, T. N., \& Bedi, H. S. (1988). Cumulus parameterization and rainfall rates: Part III. Monthly Weather Review, 116, 583-599. http://dx.doi.org/10.1175/1520-0493(1988)116<0583:CPARRP >2.0.CO;2

Krishnamurti, T. N., Ingles, K., Cocke, S., Pasch, R., \& Kitade, T. (1984). Details of low latitude medium range numerical weather prediction using a global spectral model II. Effect of orography and physical initialization. Journal of Meteorological Society of Japan, 62, 613-649.

Krishnamurti, T. N., Rohaly, G. D., \& Bedi, H. S. (1994). On the improvement of precipitation forecast skill from physical initialization. Tellus, 46A, 598-614.

Krishnamurti, T. N., Xue, J., Bedi, H. S., Ingles, K., \& Oosterhof, O. (1991). Physical initialization for numerical weather prediction over the tropics. Tellus, 43AB, 53-81.

Manobianco, J., Koch, S., Karyampudi, V. M., \& Negri, A. J. (1994). The impact of assimilating satellite derived precipitation rates on numerical simulations of the ERICA IOP 4 cyclone. Monthly Weather Review, 122, 341-365. http://dx.doi.org/10.1175/1520-0493(1994)122<0341:TIOASD >2.0.CO;2

Mathur, M. B., Bedi, H. S., Krishnamurti, T. N., Kanamitsu, M., \& Woolen, J. S. (1992). Use of satellite derived rainfall for improving tropical forecasts. Monthly Weather Review, 120, 2540-2560. http://dx.doi.org/10.1175/1520-0493(1992)120<2540:UOSDRF $>2.0 . C O ; 2$

Mlawer, E. J., Taubman, S. J., Brown, P. D., Iacono, M. J., \& Clough, S. A. (1997). Radiative transfer for inhomogeneous atmospheres: RRTM, a validated correlated-k model for the longwave. Journal of Geophysical Research, 102, 16663-16682. http://dx.doi.org/10.1029/97JD00237

Moreau, E., Lopez, P., Bauer, P., Tompkins, A. M., Janisková, M., \& Chevallier, F. (2004). Variational retrieval of temperature and humidity profiles using rain rates versus microwave brightness temperatures. Quarterly Journal of Royal Meteorological Society, 130, 827-852. http://dx.doi.org/10.1256/qj.03.118

Pan, H. L., \& Wu, W. S. (1995). Implementing a Mass Flux Convection Parameterization Package for the NMC Medium Range Forecast Model. In NMC Office Note, 409, 40pp.

Peng, M. S., \& Chang, S. W. (1996). Impacts of SSM/I retrieved rainfall rates on numerical prediction of a tropical $\begin{array}{lllll}\text { cyclone. Monthly } \quad \text { Weather } & \text { Review, 1181-1198. }\end{array}$ http://dx.doi.org/10.1175/1520-0493(1996)124<1181:IOSRRR>2.0.CO;2

Puri, K., \& Miller, M. J. (1990). The use of satellite data in the specification of convective heating for diabatic initialization and moisture adjustment in numerical weather prediction model. Monthly Weather Review, 118, 67-93. http://dx.doi.org/10.1175/1520-0493(1990)118<0067:TUOSDI >2.0.CO;2

Rajagopal, E. N., Das, G. M., Mohandas, S., Prasad, V. S., George, J. P., Iyenger, G. R., \& Preveen, K. D. (2007). Implementation of T254L64 Global Forecast System at NCMRWF. In NCMRWF Technical Report, 1-42. 
Ramesh, K. J., Basu, S., \& Begum, Z. N. (1996). Objective determination of onset, advancement and withdrawal of the summer monsoon using large scale forecast fields of a global spectral model over India. Meteorology and Atmospheric Physics, 61, 137-151. http://dx.doi.org/10.1007/BF01025702

Simpson, J., Kummerow, C., Tao, W. K., \& Adler, R. F. (1996). On the Tropical Rainfall Measuring Mission (TRMM). Meteorology and Atmospheric Physics, 60(1-3), 19-36. http://dx.doi.org/10.1007/BF01029783

Spencer, R. W., Goodman, H. M., \& Hood, R. E. (1989). Precipitation retrieval over land and ocean with the SSM/I: Identification and characteristics of the scattering signal. Journal of Atmospheric and Oceanic Technology, 6, 254-273. http://dx.doi.org/10.1175/1520-0426(1989)006<0254:PROLAO>2.0.CO;2

Spencer, R. W., Olson, W. S., Rongzhang, W., Martin, D. W., Weinman, J. A., \& Santek, D. A. (1983). Heavy thunderstorms observed over land by the Nimbus-7 Scanning Multichannel Microwave Radiometer. Journal of Applied Meteorology, 22, 1041-1046. http://dx.doi.org/10.1175/1520-0450(1983)022<1041:HTOOLB $>2.0 . C O ; 2$

Spencer, R. W. (1986). A satellite passive 37-GHz scattering-based method for measuring oceanic rain rates. $\begin{array}{lllll}\text { Journal of Climate and Applied } & \text { Meteorology, 25, 754-766. }\end{array}$ http://dx.doi.org/10.1175/1520-0450(1986)025<0754:ASPGSB >2.0.CO;2

Stanley, Q. K., \& Thomas, H. V. H. (1995). Satellite Meteorology - An Introduction. In Academic Press, 466 pp.

Tiedtke, M. (1983). The sensitivity of the time-mean large-scale flow to cumulus convection in the ECMWF model. In ECMWF Workshop on Convection in Large-Scale Models, $28^{\text {th }}$ November $-1^{\text {st }}$ December, 1983, Reading, England; 297-316.

Treadon, R. E. (1996). Physical initialization in the NMC global data assimilation system. Meteorological and Atmospheric Physics, 60, 57-86. http://dx.doi.org/10.1007/BF01029786

Treadon, R. E. (1997). Assimilation of satellite derived precipitation estimates within the NCEP GDAS. In PhD Thesis, 348pp. The Florida State University, Tallahassee, FL.

Tsuyuki, T. (1997). Variational Data Assimilation in the Tropics Using Precipitation Data. Part III: Assimilation of SSM/I Precipitation Rates. Monthly Weather Review, 125, 1447-1464. http://dx.doi.org/10.1175/1520-0493(1997)125<1447:VDAITT>2.0.CO;2

Turpeinen, O. M., Garand, L., Benoit, R., \& Roch, M. (1990). Diabatic initialization of the Canadian Regional Finite-Element (RFE) model using satellite data. Part I: Methodology and application to a winter storm. Monthly Weather Review, 118, 1381-1395. http://dx.doi.org/10.1175/1520-0493(1990)118<1381:DIOTCR >2.0.CO;2

Van Tuyl, A. H. (1996). Physical initialization with the Arakawa-Schubert scheme in the navy's operations global forecast model. Meteorological and Atmospheric Physics, 60, 47-55. http://dx.doi.org/10.1007/BF01029785

Weinman, J. A., \& Guetter, P. J. (1977). Determinations of rainfall distributions from microwave radiation measured by the Nimbus-6 ESMR. Journal of Applied Meteorology, 16, 437-442. http://dx.doi.org/10.1175/1520-0450(1977)016<0437:DORDFM>2.0.CO;2

Xu, K. M., \& Randall, D. A. (1996). A semi-empirical cloudiness parameterization for use in climate models. $\begin{array}{llll}\text { Journal of } & \text { Atmospheric 3084-3102. }\end{array}$ http://dx.doi.org/10.1175/1520-0469(1996)053<3084:ASCPFU>2.0.CO;2

Zeng, X., Zhao, M., \& Dickinson, R. E. (1998). Intercomparison of bulk aerodynamical algorithms for the computation of sea surface fluxes using TOGA COARE and TAO data. Journal of Climate, 11, 2628-2644. http://dx.doi.org/10.1175/1520-0442(1998)011<2628:IOBAAF>2.0.CO;2

Zhao, Q. Y., \& Carr, F. H. (1997). A prognostic cloud scheme for operational NWP models. Monthly Weather Review, 125, 1931-1953. http://dx.doi.org/10.1175/1520-0493(1997)125<1931:APCSFO >2.0.CO;2

Zou, X., \& Kuo, Y. H. (1996). Rainfall assimilation through an optimal control of initial and boundary conditions in a limited area mesoscale model. Monthly Weather Review, 124, 2859-2882. http://dx.doi.org/10.1175/1520-0493(1996)124<2859:RATAOC $>2.0 . C O ; 2$

Zupanski, D., \& Mesinger, F. (1995). Four dimensional variational assimilation of precipitation data. Monthly Weather Review, 123, 1112-1127. http://dx.doi.org/10.1175/1520-0493(1995)123<1112:FDVAOP >2.0.CO;2 